\section{Elevated prolactin levels in patients with Pemphigus Foliaceus}

\author{
Amina Toumi ${ }^{1,2 *}$, Khansa Chaabouni ${ }^{3}$, Olfa Abida ${ }^{1}$, Abder- \\ rahmen Masmoudi ${ }^{4}$, Hamida Turki ${ }^{4}$, Fatma Ayedi ${ }^{3}$, Hatem \\ Masmoudi ${ }^{1}$
}

${ }^{1}$ Department of Immunology, Habib Bourguiba Hospital, Sfax, Tunisia

${ }^{2}$ Department of Medical \& Health Sciences, Emirates College of Technology, Abu Dhabi, UAE

${ }^{3}$ Department of Biochimistry, Habib Bourguiba Hospital, Sfax, Tunisia

${ }^{4}$ Department of Dermatology, Hedi Chaker Hospital, Sfax, Tunisia

\begin{abstract}
Background: Pemphigus Foliaceus (PF) is a rare autoimmune bullous skin disease characterized by the production of pathogenic auto-antibodies against desmoglein 1 and the predominance of the Th2 profile. The quasi exclusivity of the disease in women in our country seems to be the direct consequence of a hormonal impregnation. This study aims to determine whether the serum levels of Follicle-Stimulating Hormone (FSH), Luteinizing Hormone $(\mathrm{LH})$, Prolactin (PRL) and Estradiol (E2) affect PF patients in the endemic southern and whether a relationship exists between these hormones and IgE /IL-4 levels.

Methods: Blood hormones, IL-4 cytokine and IgE titers were measured in 14 women with PF and 14 controls.

Results: We found significantly higher mean serum levels of PRL in patients than in control group $(p=0.023)$. Two patients $(14.28 \%)$ have hyper-prolactinemia whereas in the control group no one has hyper-prolactinemia. The hormonal studies revealed hormonal abnormalities as dominant aspects observed in $70 \%$ of pre-menopausal PF patients. We also found a positive correlation between serum PRL levels and serum LH, IgE and IL-4 levels $(r=0.593$, $p=0.025 ; r=0.679, p=0.008$ and $r=0.822, p<0.0001$, respectively), a positive correlation between serum IL-4 levels and serum LH, FSH and $\lg E$ levels $(r=0.75, p=0.002 ; r=0.668, p=0.009$ and $r=0.563$, $p=0.036$, respectively) and a positive correlation between serum $\mathrm{LH}$ and FSH levels $(r=0.948, p<0.001)$ in PF patients.

Conclusion: Our results suggest that PRL may play a role in the disease onset and highlight the importance of checking hormonal serum levels in patients with PF.

Keywords: Autoimmunity; Interleukin-4; Pemphigus Foliaceus; Prolactin
\end{abstract}

*Corresponding author: Toumi Amina, Department of Immunology, Habib Bourguiba University Hospital, 3029 Sfax, Tunisia, Tel: +21674451660; E-mail: at_toumi @yahoo.com

Citation: Toumi A, Chaabouni K, Abida O, Masmoudi A, Turki H, et al. (2016) Elevated prolactin levels in patients with Pemphigus Foliaceus. J Clin Dermatol Ther 3: 017

Received: December 07, 2015; Accepted: January 28, 2016; Published: February 15, 2016

\author{
Abbreviations \\ Abs: Antibodies \\ E2: Estradiol \\ FSH: Follicle-Stimulating Hormone \\ LH: Luteinizing Hormone \\ PF: Pemphigus Foliaceus \\ PRL: Prolactin \\ Th: T helper
}

\section{Introduction}

Pemphigus Foliaceus (PF) is a rare autoimmune bullous skin disease characterized by the presence of skin lesions and the production of pathogenic IgG4 auto-Antibodies (Abs) directed against desmoglein 1 . The production of these auto-Abs requires a preceding interaction between $\mathrm{B}$ and antigen-specific $\mathrm{T}$ helper lymphocytes. This interaction is crucial to determine the isotype of Abs produced by $B$ cells and the pattern of cytokines secreted by predominantly the T helper (Th) 2 cells such as Interleukin (IL)-4 [1]. The binding of the auto-Abs to desmosomal components induces a disjunction of desmosomal areas, which lead to the acantholysis and the formation of an intra-epidermal blister.

The clinical-epidemiological hallmarks of endemic PF, in addition to the universally immunologic mechanisms and genetic predisposition suggest the involvement of Hypothalamic-Pituitary-Gonadal (HPG) axis and hormonal factors in the aetiopathogenesis of the disease. Among these arguments we cited (i) the female predisposition, particularly during childbearing ages, (ii) the incidence of the disease in our country is even higher among young rural women (up to 20 cases/million inhabitants/year) [2-4] than in the general population (6 to 7 cases/million inhabitants/year) [2], (iii) the predictable clinical improvement during pregnancy and worsening in post-partum [5], and (iv) the increased familial or immunogenetic risks of PF in younger-onset disease [6].

Among the hormones which could be involved in the pathogenesis of this autoimmune disease we proposed the Follicle-Stimulating Hormone (FSH), the Luteinizing Hormone (LH), the Prolactin (PRL) and the Estradiol (E2). In fact, many previous studies showed that hormones; especially female hormones; can interact with the immune system and can influence immune responses of many autoimmune diseases that occur predominantly in_women [7-10]. Furthermore, in vivo and in vitro data have demonstrated that hormones could stimulate the individual cytokines level and the antibody production [11-14]. The possible physiological explanations of the potential relationship between the disease activity and LH or FSH hormones in autoimmune diseases may be through T-cell maturation, T-cell activation, or direct stimulation of cytokine production [15-17]. On the other hand, E2 and PRL share a reciprocal endocrinologic relationship. In fact, both hormones may modulate B cell function directly as well as indirectly through modulation of Th2 cytokine production [18]. Inhibition or stimulation of mononuclear cells or their cytokines by E2 or PRL may suppress or exacerbate autoimmune disease appearance. PRL has been proposed as a triggering and/or 
promoting factor in autoimmune inflammation and it has been suggested that, according to the specific pathologic context, PRL can promote, be dispensable or even protect against autoimmune pathology [19]. Published reports have demonstrated that PRL enhances immunoglobulin production and may contribute to autoimmunity development through its action on all the three mechanisms of B cell tolerance induction (negative selection, receptor editing, and anergy) $[20,21]$.

The role of hormones particularly sex hormones in the pathogenesis of PF has not been investigated until now, however, significant higher levels of PRL have been advanced as associated with severity of Pemphigus Vulgaris (PV), a second major subtype of pemphigus which is characterized by mucocutaneous blisters [22,23]. Kandpur and Reddy reported a strong association between the severity of PV and serum PRL level in a young woman [22]. In the second study, authors reported hyperprolactinemia in $25 \%$ of female patients ( 8 man and 16 women were included in this study) and a positive correlation between serum PRL levels and the extent of body surface involvement [23].

This study is conducted to determine whether the hormonal serum levels of FSH, LH, PRL and E2 are elevated in PF patients in the endemic southern area. As hormone and cytokine levels vary within the menstrual cycle and also before and after menopause [15], we hypothesized that these relative changes in hormone levels are associated with relative changes in the IL- 4 cytokine and IgE levels, which production and/or regulation is dependent on Th2 cells [24]. Thus, we investigated the relationships between these hormones, $\operatorname{IgE}$ and IL-4 levels in post- and pre-menopausal PF patients.

\section{Materials and Methods}

\section{Subjects}

This comparative case-control study, witch lasted for 1 year, was conducted in collaboration with the Department of Biochemistry of the Habib Bourguiba Hospital and the Department of Dermatology of the Hedi Chaker Hospital. All patients were diagnosed on clinical, histological (acantholysis in the upper epidermis either in the granular layer or immediately below with subcorneal bullous formation) and immunological criteria (cell surface staining) of PF [25]. Direct immunofluorescence showing IgG and/or C3 deposits most often located on the whole epidermis and less frequently predominating in the upper layers of the epidermis. Indirect immunofluorescence shows serum anti-Dsg1 Abs deposit, IgG Abs which mainly correspond to IgG4 antibodies. Anti-desmoglein 1 values were detected by a commercial ELISA kit (MBL', Nagoya, Japan).

All blood samples were taken in the third day of periodic cycle. Women with PF were subdivided according to their pre-menopausal and post-menopausal status and were matched by age ( \pm 5 years), sex and geographical origin to healthy controls. We excluded individuals (i) in period of pregnancy/lactation, (ii) with renal/hepatic failure, (iii) taking drugs that could alter serum hormones levels, such as antipsychotic medications and opium, (iv) taking oral contraceptives, and (v) also those with an abortion history.

All patients and healthy controls gave informed consentement to participate in the study.

\section{Hormonal measurement}

Blood samples, for both case and controls subjects, were taken in the morning after a period of absolute rest lasting 30 minutes and placed on ice within 2 hours of collection. Plasma was then immediately separated by centrifugation at $3000 \mathrm{rpm}$ for 20 minutes. Serums were stored at $-20^{\circ} \mathrm{C}$ until hormonal analysis were conducted. Serum concentrations of FSH (normal values 3.5-12.5 $\mathrm{mIU} / \mathrm{ml}$ for pre-menopausal and $25.8-134.8 \mathrm{mIU} / \mathrm{ml}$ for postmenopausal women), LH (normal values $2.4-12.6 \mathrm{mIU} / \mathrm{ml}$ for pre-menopausal and 7.7-58.5 $\mathrm{mIU} / \mathrm{ml}$ for post-menopausal women), PRL (normal values $4.79-23.3 \mathrm{ng} / \mathrm{ml}$ for women), E2 (normal values $18-147 \mathrm{pg} / \mathrm{ml}$ for pre-menopausal and $<58 \mathrm{pg} / \mathrm{ml}$ for post-menopausal women), were evaluated using Electro Chemil Luminescence Immunassay (Elecsys', Roche Diagnostics, Mannheim, Germany).

\section{IgE antibodies}

Total serum IgE was quantitated using BN ProSpec Nephelometer System (Siemens, Germany) as described in manufacturer's instructions (positive levels $>150 \mathrm{IU} / \mathrm{ml}$ ).

\section{IL-4 cytokine}

IL-4 were detected in the serum of PF patients only, by commercially available ELISA Quantikine kits ( $\& \& \mathrm{D}^{\circ}$, Minneapolis, Minn, USA), according to manufacturer's procedure.

\section{Statistical analysis}

The statistical analysis was performed by SPSS version 13.0 (Chicago, IL, USA). The results are considered as mean and standard deviations or median (range) for continuous variables and as a number (\%) for categorical variables. Data were compared by Student's t-tests $(n>10)$ or by the Mann-Whitney test $(n \leq 10)$ for continuous variables to evaluate differences among PF patients and controls. $P$ values less than 0.05 are considered significant. Pearson's correlation coefficients were assessed in normally distributed data to describe the relationship between hormones, IL-4 and IgE levels. Univariate regression analyses (adjusting for age and sex) were also performed.

\section{Results}

\section{Characteristics of PF patients and controls}

Clinical and demographic data of our study populations are shown in table 1. Fourteen PF women patients, 10 are pre-menopausal (Group I; mean age $35 \pm 9.1 \mathrm{yrs)}$ ) and 4 are post-menopausal (Group II; mean age $52.5 \pm 5.25 \mathrm{yrs}$ ), in active stage of the disease are included in this study. The result is a support for the increased risk of PF, particularly during childbearing ages in young women. The clinical features of PF patients show 3 principal subgroup: (i) Endemic Pemphigus Foliaceus (EPF) characterized by generalized exfoliating dermatitis which occur in young adult women, (ii) Pemphigus Erythematosus (PE) which correspond to localized lesions on the face, scalp, chest and back and is often considered as a less severe form of the disease), and (iii) Pemphigus Herpetiformis (PH) is a rare variant of $\mathrm{PF}$ where lesions may mimic dermatitis herpetiformis.

The control group consisted of 14 healthy individuals without any inflammatory or auto-immune disease. Mean age of the patients and control group were 40 and 34.71 . No statistically significant difference was noted in the demographic analysis of the two groups. 
Citation: Toumi A, Chaabouni K, Abida O, Masmoudi A, Turki H, et al. (2016) Elevated prolactin levels in patients with Pemphigus Foliaceus. J Clin Dermatol Ther 3: 017

- Page 3 of 6 -

\begin{tabular}{|c|c|c|}
\hline Features & Patients & Healthy controls \\
\hline Number & 14 & 14 \\
\hline Age & $40 \pm 11.44(24-60 \mathrm{yrs})$ & $34,71 \pm 11,2(20-60 y r s)$ \\
\hline Sex & \multicolumn{2}{|c|}{ Female } \\
\hline Origin & \multicolumn{2}{|c|}{ South of Tunisia } \\
\hline \multicolumn{3}{|l|}{ Clinical features } \\
\hline Menopausal group & 3 EPF & - \\
\hline Marital Status & 3 unmarried, 11 married & 1 unmarried, 13 married \\
\hline Number of pregnancies & $2.93 \pm 2.9$ & $1.78 \pm 1.47$ \\
\hline Number of children & $2.21 \pm 2.57$ & $1.71 \pm 1.32$ \\
\hline Disease & 2 Osteoporosis & 8 Obesity \\
\hline Mean anti-desmoglein 1 values & $>200 \mathrm{Ul} / \mathrm{mL}$ & negative \\
\hline
\end{tabular}

Table 1: Pemphigus Foliaceus patients and controls characteristic's.

EPF: Endemic Pemphigus Foliaceus; IFI: Indirect Immunofluorescence; PE: Pemphigus Erythematosus; PH: Pemphigus Herpetiformis

\begin{tabular}{|c|c|c|c|c|}
\hline PF patients & LH (2.4-12.6 mUl/ml) & FSH (3.5-12.5 mUl/ml) & E2 $(18-147 \mathrm{pg} / \mathrm{ml})$ & Prolactine $(4.79-23.3 \mathrm{ng} / \mathrm{ml})$ \\
\hline 1 & $8.38^{*}$ & $3.8^{*}$ & 32.8 & 4.29 \\
\hline 2 & $0.704^{*}$ & 7.66 & $<9^{a}$ & 9.3 \\
\hline 3 & $1.6^{*}$ & 5.5 & $12.2^{\mathrm{g}}$ & 12 \\
\hline 4 & 9.5 & $18^{ \pm}$ & 48.62 & 8.7 \\
\hline 5 & $6.4^{*}$ & $3.9^{*}$ & 115.95 & 8.5 \\
\hline 6 & 8.2 & $16.2^{ \pm}$ & $13.7^{\text {ㅁ }}$ & 13.7 \\
\hline 7 & $1.2^{*}$ & 6.3 & 19 & 9 \\
\hline 8 & 6.44 & 6.37 & 38.6 & 17.9 \\
\hline 9 & 2.95 & 4.53 & 41.78 & $37.82^{+}$ \\
\hline 10 & 5.8 & 3.5 & $190.2^{+}$ & $6.3^{-}$ \\
\hline
\end{tabular}

Table 2: Hormonal abnormalities observed in pre-menopausal PF patients.

*: Inverted LH/FSH ratio; ": Low E2 level; +: High E2 level; *: Low LH level; +: High FSH level; +: High PRL level and ": Low PRL level

Hormonal abnormalities as dominant aspects observed in

\section{PF patients}

The hormonal studies showed hyperprolactinemia $(37.82 \mathrm{ng} / \mathrm{ml}$ and $62 \mathrm{ng} / \mathrm{ml}$ ) in two (14.28\%) PF patients (one pre-menopausal and 1 post-menopausal woman). However, in the control group, no one had hyper-prolactinemia.

In the pre-menopausal PF subgroup, six (70\%) had one or more hormonal abnormalities. Decreased E2 levels, reduced LH concentration and increased levels of FSH are observed in $42.85 \%, 42.85 \%$ and $28.57 \%$ of those patients, respectively. On the other hand, 2 patients have an inverted LH/FSH ratio. In contrast, no hormonal abnormalities were observed in control group (Table 2).

\section{Hormone levels and IgE antibodies findings}

Hormonal serum levels performed in the $14 \mathrm{PF}$ patients and the 14 healthy controls are shown in table 3 . We found that all hormones in the healthy controls were within the normal range. However, the mean serum PRL level in patients was significantly higher than in the control group $(16.07 \pm 15.78 \mathrm{ng} / \mathrm{ml}$ vs $5.86 \pm 1.19 \mathrm{ng} / \mathrm{ml}$; $\mathrm{p}=0.023$; figure 1). We also found a significantly higher mean value of $\operatorname{IgE}$ Abs levels $(271.96 \pm 301.8 \mathrm{IU} / \mathrm{ml}$ vs $75.36 \pm 88.76 \mathrm{IU} / \mathrm{ml} ; \mathrm{p}=0.027$; figure 1) in patients than in the control group.
The mean sera concentration $( \pm$ SD) of hormones and IgE Abs in pre-menopausal women (group I) with $\mathrm{PF}$ and premenopausal controls are summarised in table 3. PRL and IgE Abs levels were significantly higher in pre-menopausal $\mathrm{PF}$ women compared to pre-menopausal controls $(12.75 \pm 9.6 \mathrm{ng} / \mathrm{ml}$ vs $5.67 \pm 1.07 \mathrm{ng} /$ $\mathrm{ml} ; \mathrm{p}=0.004$ and $359.36 \pm 317.68 \mathrm{IU} / \mathrm{ml}$ vs $95.7 \pm 98.7 ; \mathrm{p}=0.034)$. Similarly, serum PRL levels were significantly higher in post-menopausal PF women (group II) compared to post-menopausal controls $(25.88 \pm 24.44 \mathrm{ng} / \mathrm{ml}$ vs $6.35 \pm 1.53 \mathrm{ng} / \mathrm{ml} ; \mathrm{p}=0.021)$. The other hormonal data were unchanged in both groups $(p>0.05)$. No significant difference of PRL and IgE Abs levels were found between pre- and post-menopausal PF women.

\section{Correlation between hormone levels, IgE Abs and IL-4 in PF disease}

Pearson's correlation showed that serum PRL levels was positively correlated with serum LH, IgE Abs and IL-4 levels ( $\mathrm{r}=0.593, \mathrm{p}=0.025$; $\mathrm{r}=0.679, \mathrm{p}=0.008 ; \mathrm{r}=0.822, \mathrm{p}<0.0001$, respectively). We also found a positive correlation between serum IL-4 levels and serum LH, FSH and IgE Abs levels $(\mathrm{r}=0.75, \mathrm{p}=0.002 ; \mathrm{r}=0.668, \mathrm{p}=0.009 ; \mathrm{r}=0.563$, $\mathrm{p}=0.036$ ) and strong positive correlation between serum LH and FSH levels $(\mathrm{r}=0.948, \mathrm{p}<0.001)$ in PF patients (Table 4). 
Citation: Toumi A, Chaabouni K, Abida O, Masmoudi A, Turki H, et al. (2016) Elevated prolactin levels in patients with Pemphigus Foliaceus. JClin Dermatol Ther 3: 017

- Page 4 of 6 -

\begin{tabular}{|c|c|c|c|c|c|c|c|c|c|}
\hline & \multirow{2}{*}{ Patients $\mathrm{N}=14$} & \multirow{2}{*}{ Controls $\mathrm{N}=14$} & \multirow{2}{*}{$p$} & \multicolumn{3}{|c|}{ Group I } & \multicolumn{3}{|c|}{ Group II } \\
\hline & & & & Patients $\mathrm{N}=10$ & Controls $\mathrm{N}=10$ & $\mathrm{p}$ & Patients $\mathrm{N}=4$ & Controls $\mathrm{N}=4$ & $p$ \\
\hline Age (years) & $40 \pm 11.44$ & $34,71 \pm 11,2$ & 0.228 & $35 \pm 9.1$ & $29.2 \pm 6.21$ & 0.185 & $52.5 \pm 5.25$ & $48.5 \pm 8.54$ & 0.378 \\
\hline $\mathrm{LH}(\mathrm{mUl} / \mathrm{ml})$ & $14.85 \pm 17.13$ & $9.66 \pm 15.76$ & 0.412 & $5.11 \pm 3.25$ & $3.91 \pm 1.09$ & 0.384 & $39.21 \pm 11.55$ & $24.04 \pm 26.21$ & 0.248 \\
\hline $\mathrm{FSH}(\mathrm{mUl} / \mathrm{ml})$ & $28.98 \pm 37.4$ & $20.73 \pm 33.33$ & 0.543 & $7.57 \pm 5.2$ & $7.24 \pm 2.14$ & 0.364 & $82.52 \pm 25.14$ & $54.46 \pm 51.76$ & 0.248 \\
\hline $\mathrm{LH} / \mathrm{FSH}$ & $0.76 \pm 0.63$ & $0.52 \pm 0.22$ & 0.701 & $0.87 \pm 0.72$ & $0.58 \pm 0.2$ & 0.76 & $0.49 \pm 0.12$ & $0.39 \pm 0.25$ & 0.564 \\
\hline E2 (pg/ml) & $39.13 \pm 52.38$ & $31.23 \pm 23.1$ & 0.61 & $51.18 \pm 58.3$ & $37.53 \pm 23.87$ & 0.94 & $<9$ & $9.5 \pm 0.42$ & 0.056 \\
\hline PRL (ng/ml) & $16.07 \pm 15.78$ & $5.86 \pm 1.19$ & 0.023 & $12.75 \pm 9.6$ & $5.67 \pm 1.07$ & 0.004 & $25.88 \pm 24.44$ & $6.35 \pm 1.53$ & 0.021 \\
\hline $\operatorname{lgE}$ Abs (UI/ml) & $271.96 \pm 301.8$ & $75.36 \pm 88.76$ & 0.027 & $359.36 \pm 317.68$ & $95.7 \pm 98.7$ & 0.034 & $53.47 \pm 53.2$ & $24.52 \pm 9.49$ & 0.561 \\
\hline
\end{tabular}

Table 3: Mean of age, serum hormonal concentration and IgE titers in PF patients and healthy subjects.

Mean \pm SD are shown

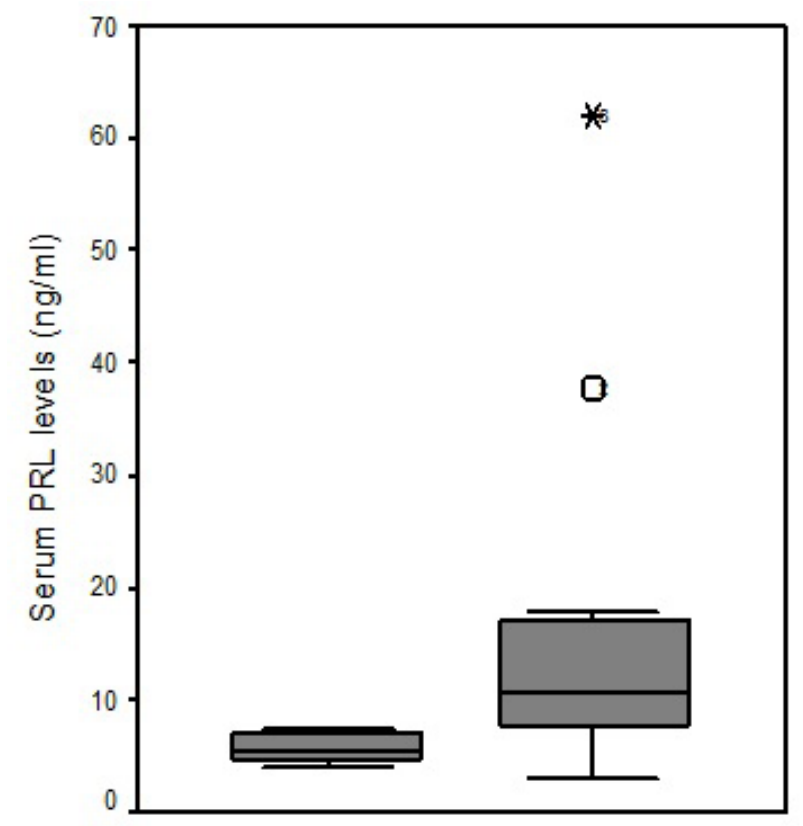

Healthy Controls PF Patients

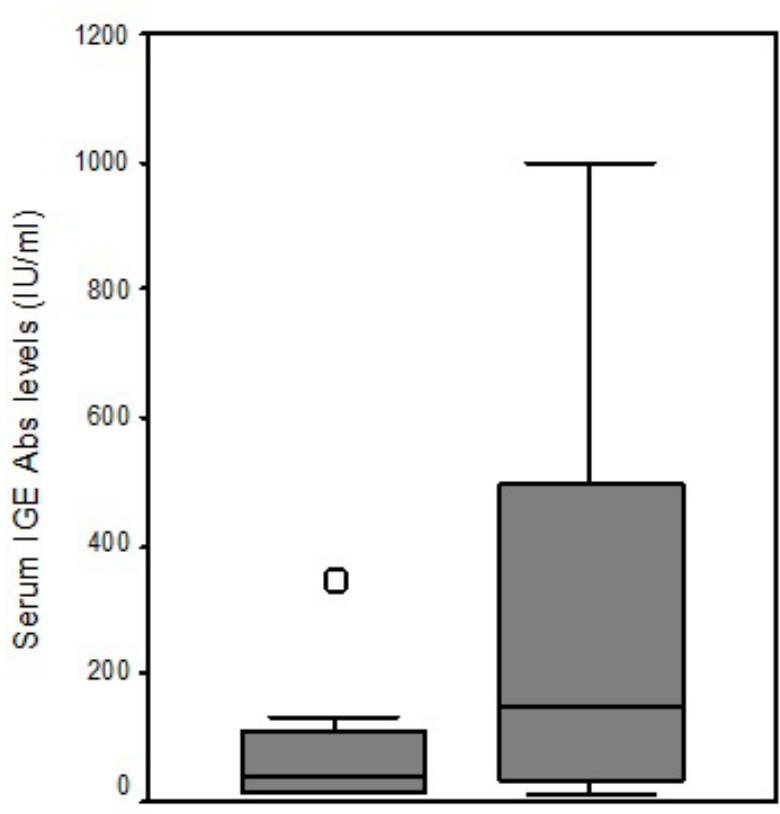

Healthy Controls PF Patients

Figure 1: Serum PRL and IgE Abs levels in PF patients and healthy controls.

Mean levels of serum PRL and IgE Abs levels were significantly higher in patients than in the control group $(p<0.05)$.

\begin{tabular}{|c|c|c|c|c|c|c|}
\hline & PRL & $\mathrm{FSH}$ & $\mathrm{LH}$ & E2 & $\lg E$ & IL-4 \\
\hline PRL & ----- & NS & $r=0.593 p=0.025$ & NS & $r=0.679 p=0.008$ & $r=0.822 p<0.001$ \\
\hline $\mathrm{FSH}$ & & ---- & $r=0.948 p<0.001$ & NS & NS & $r=0.668 p=0.009$ \\
\hline $\mathrm{LH}$ & & & ----- & NS & NS & $r=0.750 p=0.002$ \\
\hline $\mathrm{E} 2$ & & & & ---- & NS & NS \\
\hline $\lg E$ & & & & & ----- & $r=0.563 p=0.036$ \\
\hline
\end{tabular}

Table 4: Significant correlations between hormone serum levels, IgE and IL-4 serum titers in PF disease.

Table shows values of $r$ and minimal probabilities obtained after a Pearson's correlations study between hormone serum levels, IgE Abs and IL-4 in 14 PF patients; NS: indicates no significant correlation

\section{Discussion}

The female preponderance in endemic Tunisian PF disease has led to investigate the role of HPA axis activity in particular reproductive hormones in the pathogenesis of this disease. The female predominance was also verified in our prospective study which lasted for over a year. Indeed, we have compiled only female PF patients with a higher incidence of young women in childbearing age (10 pre- and 4 post-menopausal PF patients).

In this comparative case-control study, we found a significant high level of PRL hormone in PF patients compared to the healthy subjects 
Citation: Toumi A, Chaabouni K, Abida O, Masmoudi A, Turki H, et al. (2016) Elevated prolactin levels in patients with Pemphigus Foliaceus. J Clin Dermatol Ther 3: 017 .

and we also observed rates above normal range (hyper-prolactinemia) in $14 \%$ of these patients. Results of past studies have suggested a potential relationship between high levels of PRL and both organ and non-organ-specific autoimmune diseases [26].

PRL is produced by many extra pituitary sites, including immune cells and has multiple immunostimulatory effects $[27,28]$. At high concentration, PRL increases differentiation of monocytes to iDC (immature Dendritic Cells) and increases maturation of iDC to highly efficient antigen presenting $\mathrm{mDC}$ [29]. This may be a great of significance in initiating the response against Major Histocompatibility Complex (MHC)-presented self-antigens and may explain the association of high PRL concentration with autoimmune diseases. Different factors may promote hyperprolactinemia: (i) pro- or anti-inflammatory cytokines may cross the blood-brain barrier and stimulate PRL release (ii) defects in peptidergic modulators and dopamine metabolism may explain in part the hyperprolactinemia in PF or (iii) lymphocytes in active PF may increase production of PRL. According to the aforementioned, the significant increase of PRL concentrations found in our study indicates probably a high activity of the hypothalamic-pituitary axis in active disease. However, currently it is not clear if increase levels of PRL and hyper-prolactinemia are a primary phenomenon in the pathogenesis of the disease or occurs as a result of a specific endocrine axis involvement dependent on localisation of PF lesions or may merely represent an epiphenomenon associated with extensive and prolonged autoimmune response.

Another interesting point is positive significant correlations between hormones, IL-4 and IgE levels. The correlation between the PRL concentration and serum IL-4 levels indicates that PRL may enhance antibody switching through regulating IL-4 production, but this remains purely speculative. Possible physiological explanation for a potential association between disease activity and LH or FSH or PRL in PF may be through T-cell maturation, T-cell activation, or direct stimulation of cytokine production. We cannot rule out the possibility that the associations observed between LH/FSH/PRL and IL-4 cytokine or IgE serum levels may be due to their effects on the HPG axis rather than the action of LH or FSH or PRL directly or indirectly on IL-4 or IgE production; however these results suggest a direct intervention of the HPG axis in the pathogenesis of PF disease and support the possibility that immune-regulatory T-cell subsets in PF patients respond differently to LH, FSH or PRL compared with controls.

The lack of significant associations between E2 and IL-4 or IgE titers within PF patients, in comparison with control group and between pre-and post-menopausal patients give emphasis to our hypothesis that the link between the endocrine HPG axis and immune dysfunction is mainly central and PRL production is essentially extra pituitary, probably produced by immune cells. This link could be represented by PRL that can modulate GnRH pulsatility and thus FSH and LH levels. In fact, PRL seems to be the main factor; independent of age, LH/FSH ratio or E2; implicated in this immune dysfunction as it is positively correlated with IgE Abs and IL-4 levels and significantly higher in PF group than in control.

It is well known that pemphigus disease is associated with Th2 cells [1]. This Th2-dependency associates the IgG4 and IgE responses mainly during acute onset disease [30,31]. Indeed, in our study we also observed a significant increasing level of IgE Abs in patients than in controls. The requirements for the class switch to IgG4 and to IgE are similar and both depend on IL-4/IL-13 which production was probably induced or exacerbate by elevated levels of PRL in PF patients.

\section{Conclusion}

The role of female hormones in the development of PF is undoubtedly complex and challenging to study. Although its limitation due to relatively small number of patients, this preliminary study shows an interesting relationship between elevated serum levels of PRL, IL4 and IgE in PF patients. Further studies with larger cohorts and combining clinical and experimental data are needed to fully elucidate the role of HGP axis and especially PRL in the pathogenesis of this enigmatic disorder.

\section{Conflict of Interest Statement}

The authors declare no conflict of interest.

\section{Acknowledgment}

This work was supported by grants from DGRST (Direction Générale de la Recherche Scientifique et Technique, Tunisie).

\section{References}

1. Caproni M, Giomi B, Cardinali C, Salvatore E, Pestelli E, et al. (2001) Further support for a role for Th2-like cytokines in blister formation of pemphigus. Clin Immunol 98: 264-271.

2. Bastuji-Garin S, Souissi R, Blum L, Turki H, Nouira R, et al. (1995) Comparative epidemiology of pemphigus in Tunisia and France: unusual incidence of pemphigus foliaceus in young Tunisian women. $J$ Invest Dermatol 104 : 302-305.

3. Kallel Sellami M, Ben Ayed M, Mouquet H, Drouot L, Zitouni M, et al. (2004) Anti-desmoglein 1 antibodies in Tunisian healthy subjects: arguments for the role of environmental factors in the occurrence of Tunisian pemphigus foliaceus. Clin Exp Immunol 137: 195-200.

4. Abida O, Kallel-Sellami M, Joly P, Ben Ayed M, Zitouni M, et al. (2009) Anti-desmoglein 1 antibodies in healthy related and unrelated subjects and patients with pemphigus foliaceus in endemic and non-endemic areas from Tunisia. J Eur Acad Dermatol Venereol 23: 1073-1078.

5. Bastuji-Garin S, Turki H, Mokhtar I, Nouira R, Fazaa B, et al. (2002) Possible relation of Tunisian pemphigus with traditional cosmetics: a multicenter case-control study. Am J Epidemiol 155: 249-256.

6. Abida O, Masmoudi A, Rebaï A, Ben Ayed M, Mahfoudh N, et al. (2009) The familial feature of Tunisian endemic pemphigus foliaceus. Br J Dermatol 161: 951-953.

7. Khan D, Ansar Ahmed S (2016) The Immune System is a Natural Target for Estrogen Action: Opposing Effects of Estrogen in Two Prototypical Autoimmune Diseases. Front Immunol 6: 635.

8. Airas $L$ (2015) Hormonal and gender-related immune changes in multiple sclerosis. Acta Neurol Scand 132: 62-70.

9. Tan IJ, Peeva E, Zandman-Goddard G (2015) Hormonal modulation of the immune system - A spotlight on the role of progestogens. Autoimmun Rev 14: $536-542$

10. Ramien C, Taenzer A, Lupu A, Heckmann N, Engler JB, et al. (2016) Sex effects on inflammatory and neurodegenerative processes in multiple sclerosis. Neurosci Biobehav Rev.

11. Araneo BA, Dowell T, Diegel M, Daynes RA (1991) Dihydrotestosterone exerts a depressive influence on the production of Interleukin-4 (IL-4), IL-5, and gamma-interferon, but not IL-2 by activated murine T cells. Blood 78: 688699.

12. Calippe B, Douin-Echinard V, Laffargue M, Laurell $H$, Rana-Poussine V, et al. (2008) Chronic estradiol administration in vivo promotes the proinflammatory response of macrophages to TLR4 activation: involvement of the phosphatidylinositol 3-kinase pathway. J Immunol 180: 7980-7988. 
Citation: Toumi A, Chaabouni K, Abida O, Masmoudi A, Turki H, et al. (2016) Elevated prolactin levels in patients with Pemphigus Foliaceus. JClin Dermatol Ther 3: 017

13. Gilmore W, Weiner LP, Correale J (1997) Effect of estradiol on cytokine secretion by proteolipid protein-specific $T$ cell clones isolated from multiple sclerosis patients and normal control subjects. J Immunol 158: 446-451.

14. Chavez-Rueda K, Hérnández J, Zenteno E, Leaños-Miranda A, Legorreta-Haquet MV, et al. (2005) Identification of prolactin as a novel immunomodulator on the expression of co-stimulatory molecules and cytokine secretions on T and B human lymphocytes. Clin Immunol 116: 182-191.

15. Kåss AS, Lea TE, Torjesen PA, Gulseth HC, Førre ØT (2010) The association of luteinizing hormone and follicle-stimulating hormone with cytokines and markers of disease activity in rheumatoid arthritis: a case-control study. Scand J Rheumatol 39: 109-117.

16. Bhatia A, Sekhon HK, Kaur G (2014) Sex hormones and immune dimorphism. ScientificWorldJournal 2014: 159150

17. Bouman A, Heineman MJ, Faas MM (2005) Sex hormones and the immune response in humans. Hum Reprod Update 11: 411-423.

18. Cejkova P, Fojtikova M, Cerna M (2009) Immunomodulatory role of prolactin in diabetes development. Autoimmun Rev 9: 23-27.

19. Costanza M, Binart N, Steinman L, Pedotti R (2015) Prolactin: a versatile regulator of inflammation and autoimmune pathology. Autoimmun Rev 14 223-230.

20. Peeva E, Venkatesh J, Michael D, Diamond B (2004) Prolactin as a modulator of B cell function: implications for SLE. Biomed Pharmacother 58: 310-319.

21. Saha S, Tieng A, Pepeljugoski KP, Zandamn-Goddard G, Peeva E (2011) Prolactin, systemic lupus erythematosus, and autoreactive $B$ cells: lessons learnt from murine models. Clin Rev Allergy Immunol 40: 8-15.
22. Khandpur S, Reddy BS (2002) An unusual association of pemphigus vulgaris with hyperprolactinemia. Int J Dermatol 41: 696-699.

23. Fallahzadeh MK, Lashkarizadeh H, Kamali-Sarvestani E, Namazi MR (2010) Elevation of serum prolactin levels in patients with pemphigus vulgaris: a novel finding with practical implications. J Am Acad Dermatol 62: 1071-1072.

24. Ferrer M, Kaplan AP (2007) Progress and challenges in the understanding of chronic urticaria. Allergy Asthma Clin Immunol 3: 31-35.

25. Jarzabek-Chorzelska M, Jablonska S, Kolacinska-Strasz Z, Sulej I (2002) Immunopathological diagnosis of pemphigus foliaceus. Dermatology 205: 413-415.

26. Shelly S, Boaz M, Orbach H (2012) Prolactin and autoimmunity. Autoimmun Rev 11: 465-470.

27. De Bellis A, Bizzarro A, Pivonello R, Lombardi G, Bellastella A (2005) Prolactin and autoimmunity. Pituitary 8: 25-30.

28. Orbach H, Shoenfeld $Y(2007)$ Hyperprolactinemia and autoimmune diseases. Autoimmun Rev 6: 537-542.

29. Matera L, Mori M, Galetto A (2001) Effect of prolactin on the antigen presenting function of monocyte-derived dendritic cells. Lupus 10: 728-734.

30. Bruns GR, Ablin RJ (1979) Levels of serum IgE in patients with Brazilian pemphigus foliaceus and pemphigus vulgaris. Allergol Immunopathol (Madr) 7: $407-410$

31. Sitaru C, Mihai S, Zillikens D (2007) The relevance of the IgG subclass of autoantibodies for blister induction in autoimmune bullous skin diseases. Arch Dermatol Res 299: 1-8. 